\title{
Organizational learning across multi-level networks
}

\author{
Paola Zappa ${ }^{\mathrm{a}, *}$, Garry Robins ${ }^{\mathrm{b}}$ \\ a Faculty of Economics and Social Network Analysis Research Center (SoNAR), University of Lugano, Switzerland \\ ${ }^{\mathrm{b}}$ Melbourne School of Psychological Sciences, The University of Melbourne, Australia
}

\section{A R T I C L E I N F O}

\section{Article history:}

Received 31 January 2014

Received in revised form 9 March 2015

Accepted 12 March 2015

Available online 24 April 2015

\section{Keywords:}

Multilevel theory of organization

Organizational learning

Knowledge transfer

Boundary spanning

Multilevel Exponential Random Graph

Models

\begin{abstract}
A B S T R A C T
This paper examines organizational learning through a multilevel network lens. We assess how interpersonal knowledge transfer is sustained by the organizational structure of interunit work-flow ties and by the level of specialism of the connected units.

To do this, we apply Multilevel Exponential Random Graph Models on data collected in a multiunit government institution in Italy.

Results indicate that our approach allows simplifying and better understanding of organizational learning. Units are more likely to retain knowledge transfer ties within their boundaries. Unit boundaryspanning tends to occur only when knowledge transfer ties are sustained by hierarchical interunit work-flow ties.
\end{abstract}

(C) 2015 Elsevier B.V. All rights reserved.

\section{Introduction}

Organizational learning, the process by which organizations generate, disseminate and exploit knowledge, translating it into innovation (March and Simon, 1958; Cyert and March, 1963; March, 1991) is a key topic in organizational studies.

An extensive literature has demonstrated that learning is a never-ending process, which contributes significantly to organizational growth, performance and survival (March, 1996). Because of these benefits, significant attention has been devoted to understand how learning occurs (Argote et al., 2003). A crucial mechanism consists in learning from the experience of others, either within or across the organizational boundaries. Learning from others requires some form of knowledge transfer, which is made possible mainly by interpersonal interaction among organizational members (Krackhardt and Hanson, 1993; Tushman, 1977). Interpersonal interaction, in fact, allows people to search for (i.e., 'look and identify') knowledge available in some parts of the organization and to transfer ('move and incorporate') it to other parts (Hansen, 1999, p. 83).

In examining knowledge transfer within the organization which is the focus of this paper - the capability of interpersonal relations to connect different units, divisions and departments

\footnotetext{
* Corresponding author at: Faculty of Economics, University of Lugano, Via G. Buffi, 13 - 6904 Lugano, Switzerland. Tel.: +41 0586664471.

E-mail addresses: paola.zappa@usi.ch (P.Zappa),garrylr@unimelb.edu.au (G. Robins).
}

has been particularly investigated. Because organizational units, divisions and departments are pools of homogenous knowledge (Reagans and McEvily, 2003; Tortoriello and Krackhardt, 2010), searching in different units across organizational boundaries increases the heterogeneity of knowledge available and promotes learning (Beckman and Haunschild, 2002).

Since people are generally reluctant to cross-cut the boundaries defined around their units, several papers have attempted to identify how boundary spanning can be facilitated (Argote and Epple, 1990; Tortoriello et al., 2012). These studies have focused mostly on characteristics of the people as well as on types and structures of the relations among them (Burt, 2004; Dokko et al., 2014), disregarding the context in which relations occur.

This paper assesses whether and how the characteristics of the organization, and of the organizational structure in particular, can affect the presence of boundary-spanning ties. We examine the effect of the existence of work-flow ties connecting the units among which people are expected to search and transfer knowledge. The purpose of such an investigation is to provide a better understanding of the extent to which boundary-spanning relations of informal knowledge search-transfer at interpersonal level can be sustained by the formal work-flow ties between organizational units (Reagans and McEvily, 2003).

We emphasize the benefits of addressing these purposes by conceiving organizations as hierarchical systems of nested relations - i.e., multilevel network systems. We show how such an approach would allow a better representation of the interdependences between formal and informal relations and a clear assessment of the role of both. 
We provide empirical evidence on this claim specifying and estimating newly developed Multilevel Exponential Random Graph Models (MERGMs - Wang et al., 2013, 2015). They represent a significant improvement on previous multilevel methods that are unable to analyze hierarchical systems of nested relations in depth. Standard Hierarchical Linear Models (HLMs) account for individual membership to a unit only. Assuming that either lower- (i.e., individual) or higher- (i.e., unit) level actors are independent from one another, conditional on the nesting structure of individuals within units, HLMs do not fit the structure of network then, do HLMs allow modeling interdependences among actors either within levels (i.e., interpersonal and interunit network separately) or between levels (i.e., associations and overlaps between the two network structures). The structural linked design (Lazega et al., 2008), popular in network studies, relaxes some assumptions of HLMs and, therefore, addresses some of their limitations. This approach respects the multi-level nature of the data, but models only some kinds of interdependences between the ties at the two levels.

In the empirical part of the paper, we specify and estimate MERGMs on original relational data that we have collected in a multiunit division of a regional government institution based in Northern Italy. Comparing the results of MERGM estimations with those of simpler ERGMs (Robins et al., 2007; Snijders et al., 2006), we show the advantages of addressing organizational learning through the multilevel network lens.

\section{Theoretical background and motivation}

\subsection{Organizational learning as interpersonal knowledge sharing}

Informal interpersonal networks are one of the main conduits through which knowledge flows within the organization (Krackhardt and Hanson, 1993). Informal ties of advice seeking and knowledge searching, in particular, allow individuals to have access to knowledge accumulated by close contacts (Reagans and Zuckerman, 2001; Zaheer and McEvily, 1999), either inside or outside the organization (Argote et al., 2003).

Indeed, informal interpersonal networks can provide access to heterogeneous others (Beckman and Haunschild, 2002; Beckman et al., 2004). Heterogeneity is a potential source of benefits for either the organization, or the individuals who, improving their knowledge pools, can contribute more effectively to organizational activities. The diverse experiences of network partners draw attention to existing information (Fiske and Taylor, 1984) and provide individuals and organizations with a variety of normative, instrumental and procedural information for better causal inference on the possible consequences of specific actions (Beckman and Haunschild, 2002). Hence, a higher level of network heterogeneity (Reagans and McEvily, 2003; Williams and O'Reilly, 1998) increases individual creativity and innovativeness (Burt, 2004) as well as organizational productivity (Beckman et al., 2004) and competitiveness (Argote and Ingram, 2000).

In multiunit organizations, heterogeneity of information has been repeatedly linked to the idea of connecting individuals affiliated to different units - i.e., the idea of spanning formal boundaries defined around organizational units (Reagans and McEvily, 2003; Tortoriello and Krackhardt, 2010). In an attempt to understand why some ties are more likely than others to span unit boundaries, extant literature has examined various aspects of the relations and of the people involved in them. The position of some people within the knowledge transfer network can make them more capable of cross-cutting organizational boundaries. This is the case, for instance, of people with gate-keeping roles - i.e., people who are in contact with other organizations and receive information and knowledge from them, then transferring the knowledge acquired within the organization (Burt, 2004). The strength of the relation can also matter. Evidence in this respect, however, is fairly mixed. Some studies have suggested that strong and mutual ties of knowledge search are more likely to cross-cut unit boundaries and to give access to valuable knowledge (Reagans and McEvily, 2003; Tortoriello et al., 2012). Others have found that weak ties are more effective (Granovetter, 1973).

A second and underexplored driver of boundary-spanning ties is the organization itself, and the organizational structure in particular. Especially in large organizations, the dispersion of knowledge across units and the difficulty for people to interact with colleagues affiliated to other units can make the search-transfer process tougher. People may even not be aware of where knowledge on some peculiar issues resides (Burt, 1992). Indeed, some units may be more knowledgeable than others, and more attractive as targets of knowledge searching processes. It may be the case of units specialized in R\&D (Hansen, 1999) or of units whose activities are highly integrated with those of other companies. By contrast, units whose knowledge is very complex, general, or specific to just some processes or projects, may be excluded by the search-transfer of knowledge (Zander and Kogut, 1995).

A clear formalization of these ideas consists in admitting that knowledge resides in multiple reservoirs (McGrath and Argote, 2001) and that it is mobilized by people within the range of possible patterns that the organization offers. In other words, the knowledge search-transfer problem is a matter of 'discretion with constraints' (Kleinbaum et al., 2013). The organizational structure and the diversity of knowledge that it offers can both sustain and constrain the search and transfer of knowledge across boundaries.

\subsection{Organizations as multilevel network systems}

The Multilevel Network Theory of Organizations (Moliterno and Mahony, 2011) provides the theoretical framework for addressing the influence of the organizational structure on the search-transfer of knowledge. Claiming that organizations would be better conceived as hierarchical social systems with multiple and partially nested levels of action (March and Simon, 1958), this theory makes explicit a multilevel network conceptualization that empirical studies have been claiming for long time (Baum and Ingram, 2002; Brass et al., 2004; Oh et al., 2006).

According to this perspective, organizations are systems shaped by mechanisms of grouping and of interaction. The former implies that people are members in units, departments or work teams. Units, departments and work teams may be part of branches or subsidiaries. Subsidiaries, in turn, are contained in companies (Granovetter, 2005). The membership in the same group - a unit in our case - and the characteristics of the group can create interdependence among people (Hitt et al., 2007; Kozlowski and Klein, 2000), affecting their propensity to interact with one another.

The interaction mechanism implies that actors at each organizational level are linked to one another by relations. Ties can be observed between people, units, work-teams, departments and subsidiaries within organizations (Borgatti and Foster, 2003). Individuals are typically linked by informal relations, like advice seeking, knowledge transfer or friendship. In multi-unit companies, aggregate entities like units are usually connected by formal relations of hierarchical reporting or work-flow (McEvily et al., 2014). These links are due to allocation and integration of tasks among units and determine the organizational structure. Hierarchical reporting relations represent the hierarchical ordering among units, as displayed in the organizational chart (Krackhardt and Hanson, 1993). Work-flow ties capture formal relations of cooperation among units (Kleinbaum et al., 2013) and are linked to the accomplishing of day to day activities. 
Since lower-level actors are nested in higher-level actors, at least some lower-level relations may be associated with higher-level relations. So, the structure of relations at one level is likely to affect the structure of relations at another level (Moliterno and Mahony, 2011). Also characteristics of higher-level actors may affect the relations between lower-level actors.

Accounting for these dependences would provide a more realistic representation of organizational learning and would allow assessment of whether membership in the same unit, links between units, and characteristics of these units, increase the chances of searching and transferring knowledge across boundaries.

\subsection{Organizational learning across levels}

'Units, departments or subsidiaries are foci around which joint activities are organized' (Feld, 1981, p. 1016). '[Unit] boundaries are established by design and maintained by official administrative rules, explicit systems of incentives, and formal resource allocation' (Lomi et al., 2014, p. 439). Affiliation to the same unit provides people with the advantages of physical proximity and opportunities of repeated interaction, which, in turn, enable people to search and transfer knowledge within unit boundaries.

Membership in units may also lead people to develop a sense of identification, in terms of shared interests, values and worldviews. Identification consolidates the boundaries around units and decreases the likelihood of observing network ties across units. Hence, the more strongly people identify with their unit the more unlikely they are to cross-cut its boundaries (Kogut and Zander, 1996; Lomi et al., 2014).

People's opportunities for interacting with colleagues in other units may also be exogenously reduced. This happens, for instance, when people are affiliated to a unit that competes with others for a limited set of internal resources (Tsai, 2002). Because of the fear of opportunistic behaviors, units may decide not to cooperate with one another and impose the same choice on their employees.

Finally, even when interaction is not prevented, the searchtransfer process may not take place. When knowledge available across units is too heterogeneous, people may find it difficult to understand, or to mobilize and integrate it (Nonaka, 1994). Because of limited absorptive capacity (Cohen and Levinthal, 1990), people learn by associating new ideas with what they already know and may be unable to exchange knowledge with colleagues located in parts of the organization with which there is no common knowledge base (Reagans and McEvily, 2003). To develop an effective absorptive capacity, exposing an individual briefly to the relevant prior knowledge may be insufficient. Intensity of effort is critical (Cohen and Levinthal, 1990).

For all these reasons, we expect that units are generally more likely to retain ties within their boundaries and people are unlikely to cross-cut them, in search of heterogeneous knowledge.

$\mathbf{H}_{\mathbf{1}}$. Knowledge transfer ties are more likely to be observed between individuals affiliated to the same unit.

When work-flow ties connect two organizational units, people affiliated to them are more likely to cooperate in their day to day activities, although usually with a lower frequency than within units. Existence of these mandatory interunit ties can create a larger convenience sample within which people search their knowledge sharing partners (Kleinbaum et al., 2013). Also, work-flow ties can reduce the costs and efforts of creating and maintaining boundaryspanning ties (McEvily et al., 2014) and can increase absorptive capacity, exposing people repeatedly to the knowledge available in the connected unit. For a similar reason, work-flow ties can contribute also to signaling: they enhance people's awareness of the type of knowledge available within the connected units (Ren and Argote, 2011). So, even if people are not directly required to cooperate, they may be more keen to sample the knowledge of the connected unit, when in need of it.

A similar evidence has been observed for production processes (Argote and Epple, 1990; Epple et al., 1991). Teams that work within the same plant, and deal with connected tasks, are likely to be required to cooperate and share activities, and, because of this, tend to become dependent on one another. As a consequence, teams within the same plant are also likely to share more knowledge than teams located in separated production facilities. Likewise, workflow ties between units - even when they do not imply geographic proximity - are likely to require people in connected units to cooperate, and therefore can produce the same result as for people in shared plants.

The assumption that formal organizational ties, codified in rules and procedures, can enable the formation of informal links has been verified at the micro level itself. It is well known that when people are required to coordinate their efforts and to cooperate in formal organizational processes, they tend also to build informal relations, like knowledge exchange - no matter whether they are member in the same unit or not (Soda and Zaheer, 2012). Drawing on these complementary streams of studies, we claim as follows.

$\mathbf{H}_{2}$. Knowledge transfer ties are more likely to be observed between individuals affiliated to different units when the units are linked by work-flow ties.

The existence of work-flow ties between two units should indicate that their knowledge pools are - or are likely to become over time - complementary or similar to some extent. This complementary or similarity, however, may not suffice to ensure that people affiliated to a unit will search knowledge in a connected other. Not all the knowledge is equally easy or interesting to transfer. ${ }^{1}$ Uncodified knowledge, for example, tends to require significant effort and may be difficult to transfer even among people working together (Polanyi, 1966). Some knowledge may be too specific to some areas of interest and, therefore, difficult to apply to other areas. Other knowledge may be too generic and, then, poorly informative or new. Because of this dichotomy between specialist and generalist knowledge, organizations that exploit mainly one or the other type (Carroll, 1985) - but the same considerations can be easily extended to units within the same organization - have usually different learning processes. Generalists are less likely to learn from their own experience (Barnett et al., 1994; Ingram and Baum, 1997), particularly when this experience has heterogeneous causes. This is due to the scant ability of these organizations to filter, understand and elaborate knowledge, especially specific one. This difficulty to deal with heterogeneous knowledge suggests that generalists may be also less likely to learn from the experience of others. Such evidence can make generalists - and generalist units - undesirable partners for knowledge search-transfer. They are unlikely to be able both to transfer their experience to others and to benefit from the experience of others, which is usually different from their own experience. Hence, people affiliated to generalist units are less likely to be involved in knowledge search-transfer, especially with colleagues who are member in specialist units. These, indeed, have much higher learning rates and are, therefore, unlikely to promote interaction with members of generalist units. We hypothesize as follows.

$\mathbf{H}_{3}$. Knowledge transfer ties are less likely to be observed between individuals affiliated to different units when the units linked by work-flow ties have a different level of specialism.

\footnotetext{
1 We are indebted to an anonymous reviewer for suggesting this point.
} 
We propose to address these research hypotheses by taking a multilevel network perspective (Moliterno and Mahony, 2011). This requires conceptualizing knowledge search as the network of seeking new ideas among individuals (i.e., the micro- or lower-level network) and work-flow across the organization as the network of cooperation on day to day activities among units (i.e., the macroor higher-level network). Individuals are linked to units by means of membership ties (Lazega et al., 2008).

\section{Methods and data}

\subsection{Representing multilevel network data}

Multilevel Exponential Random Graph Models (Wang et al., 2013,2015 ) are the only existing method which directly assesses network interdependences across levels. MERGMs are a new class of ERGMs for multilevel network data.

Let $M=[A, X, B]$ denote the network variable for a $(u, v)$ two-level network, and $m=[a, x, b]$ the corresponding realizations. $M$ consists of a network $A=\left[A_{h u}\right]$ representing a relation among a set $U$ of higher-level actors with $h, u$ nodes in $U$; a network $B=\left[B_{i v}\right]$ representing a relation among a set $V$ of lower-level actors with $i, v$ nodes in $V$; and a two-mode network $X=\left[X_{i h}\right]$ representing the affiliation of $i$ to $h$. Let, finally, $Y=\left[Y^{A}, Y^{B}\right]$ denote the set of attributes for actors of levels $A$ and $B$, and $y=\left[y^{A}, y^{B}\right]$ their realizations. ${ }^{2}$

MERGMs with actor attributes are expressed as follows:

$\operatorname{Pr}(M=m \mid Y=y)=\frac{1}{\kappa} \exp \sum_{Q}\left\{a_{Q} Z_{Q}^{T}(m)+\theta_{Q} Z_{Q}^{T}(m, y)\right\}$

- $Q$ represents a potential network configuration. The summation $\Sigma$ is over all different configurations in the model.

- $Z_{Q}(m)$ is the vector of network structural effects or configurations - i.e., statistics which involve network tie variables only.

- $a_{Q}$ is the vector of parameters corresponding to the structural effects $Z_{Q}(m)$.

- $Z_{Q}(m, y)$ is the vector of attribute effects or configurations - i.e., statistics which account for the interaction between network tie variables and nodal attribute covariates.

- $\theta_{Q}$ is the vector of parameters corresponding to the attribute effects $Z_{Q}(m, y)$.

- $\kappa$ is a normalizing constant included to ensure that (1) is a proper probability distribution.

MERGMs parameterize a number of configurations. A first group involves the standard ERGM effects that model each network separately (Robins et al., 2009; Snijders et al., 2006). Typical of the multilevel modeling are the effects that account for the interdependence between two or three networks (Wang et al., 2013). More detail on the configurations included in our empirical models is provided below. MERGM estimation is performed with the Monte Carlo Markov Chain Maximum Likelihood simulation-based method (Snijders, 2002). The software used is MPNet (Wang et al., 2013).

\subsection{The dataset}

\subsubsection{Data}

We use original data that we have collected in a multi-unit division of a regional government institution in Northern Italy.

Multi-unit organizations are ideal for addressing our research hypotheses. Their formal structure implies both division and

\footnotetext{
2 MERGM specifications that incorporate exogenous nodal covariates are known also as Social Selection Models for Multilevel Networks (Wang et al., 2015). For simplicity, we will refer to them as MERGMs with actor attributes.
}

integration of activities between units. This holds especially when the organization is in charge of specific tasks, as a division is expected to be. In public administration, mechanisms of cooperation tend to be clearly defined and formalized. Then, work-flow ties should be easily identifiable. Interunit ties can provide organizational members with opportunities for interacting and building relations with colleagues that are members in other units. These relations can be crucial in public institutions. Since they have usually stable tasks and routines and rarely conceive introducing new practices as a priority (Damanpour, 1991), informal relations of advice seeking or new ideas sharing are likely to be the main conduits through which knowledge circulates within the organization. Understanding whether knowledge sharing exists and how it takes place is, therefore, vital.

The division examined is part of the local government institutions of one of the largest Italian regions. The regional government includes several agencies and divisions, each in charge of different aspects of the regional policies. Because of their specificity, divisions are autonomous from one another and unlikely to cooperate. The most ties involving the multi-unit division are likely to take place among its members. Hence, we set the boundaries at the division level and analyzed it completely. The division is involved in organizational aspects of the government itself - i.e., in designing, implementing and managing information systems, ICT and human resources strategies for all the regional institutions. The organization employs 243 people and is articulated in ten units. One unit coordinates the work of the whole division, while the others deal with strategic or operational activities with various levels of specialism. They are likely to require integration among activities. Thus, some units are likely to cooperate on a regular basis.

Data collection was conducted in 2011, with the support of the division managers. The multilevel network was reconstructed using a brief questionnaire designed and administered via email to all the division's employees. In the relational section of the questionnaire employees were presented with the list of names of their 242 colleagues and were asked to nominate those with whom they interact regularly. The number of nominations was not fixed.

We used the same questionnaire for collecting demographic information that might affect participation in knowledge searchtransfer. $^{3}$ We obtained an $81 \%$ response rate, a total of 196 respondents. We restricted the network to our respondents, ignoring non-respondents. ${ }^{4}$

\subsubsection{Variables and measures}

3.2.2.1. Network variables. To build the interpersonal knowledge transfer network $B$, sized $(196 \times 196)$, we asked employees to nominate whom they approach for new ideas ('Which colleagues do you ask new ideas or innovative solutions on how to improve your work activities?') and how often. Searching new ideas allows identifying explicitly the flow of valuable knowledge, which can contribute to learning. We collected frequency of interaction on a three level ordinal scaling ( 1 ='from once a month to once a week', 2 ='from once a week to once a day', and 3 = 'more than once a day'). Then, we converted answers into network format assuming that a tie exists

\footnotetext{
3 We supplemented missing observations on these variables using company records, which store a set of demographic and work-related data for each employee.

${ }^{4}$ ERGMs have been designed for complete networks. Therefore, modeling a network with missing data could represent a serious issue and result in biased estimates of the model parameters (Handcock and Gile, 2010). Simulation studies, however have proven that the main properties of the network are somehow preserved if the non-response rate is lower than $30 \%$ (Kossinets, 2006). Drawing on this insight once verified that non-respondents do not significantly differ from respondents for either relational (i.e., the average indegree) or individual characteristics, we decided to delete non-respondents and to analyze the resulting sub-network. The reduction of the sample size affected almost equally the size of all the units.
} 
from actor $i$ to actor $j$ when $i$ nominates $j$ as a source of new ideas. As MERGMs are defined for binary relations only, ties had to be dichotomized. We chose to adopt a broad definition of the network relation and dichotomized the ties at the minimum value, thereby including all the interactions, implying exchange of new ideas on a monthly frequency at least. ${ }^{5}$

To build the interunit work-flow network $A$, sized $(10 \times 10)$, we required a more complex procedure. Because interunit work-flow was not codified in official documents, we relied on data reporting on systematic cooperation among people and we transformed them in interunit ties (Hansen, 1999). We asked employees to nominate those with whom they regularly exchanged information on day to day activity ('Which colleagues do you ask information on how to perform your day-to-day work activities?') and how often, as above. In doing so, we aimed to capture the systematic flow of information due to activity integration (Mintzberg, 1979).

Work-flow ties have been repeatedly defined as hierarchical relations of cooperation among homogenous groups of people, like units (Kleinbaum et al., 2013). '[T]hese regularly occurring interdivision contacts do not belong to any one individual but [are] referred to as divisional-level or group-level contacts' (Hansen, 1999, p. 91). Ties systematically observed between people affiliated to different units can be thought of as traces left by the existence of cooperation ties between the units. ${ }^{6}$ Ties between people due to daily activities are unlikely to depend on individual choices. They are mandatory and due to the membership in a group, to which other groups want to have access. Because people affiliated to the same unit are likely to have access to a similar set of information, they could be perceived as interchangeable by colleagues in other units (Kleinbaum et al., 2013).

We transformed these work-flow ties between employees across units into ties between the units of which employees are members. The generic element of network $A, a_{h k}$, represents the number of employees affiliated to unit $h$ who seek information from employees affiliated to unit $k$.

$a_{h k}=\sum_{i, j}^{n} b_{i j}$

where $i \in h, j \in k ; h \neq k$.

We dichotomized the ties testing different criteria: (a) at the minimum value, so that all the values of $a_{h k}$ equal to or greater than 1 were set to 1 ; (b) at the median value per unit, so that for unit $h$ only values of $a_{h k}$ equal to or greater than the median of all $a_{h k}$ were set to 1 ; (c) at the mean value per unit, so that for unit $h$ only values of $a_{h k}$ equal to or greater than the mean of all $a_{h k}$ were set to 1 . Criterion a. led to a very dense network, where a

\footnotetext{
5 This low threshold is also consistent with the setting. Since public administration is a fairly static work setting, not particularly sensitive to learning, spontaneous knowledge sharing is unlikely to be a frequent activity. We subsequently built the interpersonal network using more stringent criteria of dichotomization and verified that the salient characteristics of the network - i.e., degree distribution, reciprocity and clustering coefficients - are almost invariant to the dichotomization criterion proposed or change all in a similar proportion as the threshold increases. In short, we regard the dichotomization rule we adopted as robust in terms of constructing the network. It is the most generous in assessing whether there is substantial heterogeneity in knowledge sources.

6 Studies on organizational social networks have frequently represented relations under the assumption of isomorphism across levels. Multilevel networks have been reduced to single-level multiplex networks, consisting of a set of actors (individuals or units) and two relations. Some studies have represented a formal relation among higher-level actors as the "co-working" or "reporting to" relation among organizational members (Rank et al., 2010) affiliated to the higher-level actors, and analyzed it together with an informal relation. Other studies have aggregated and analyzed the both relations at the interunit level (Tsai, 2002). This approach does not account for the multilevel nature of the organization. Hence, it is likely to alter the relationships in the data and to cause model misspecification - an issue well documented in the literature on standard multilevel modeling (Rousseau, 1985).
}

Table 1

Network descriptive for interpersonal and interunit networks.

\begin{tabular}{lll}
\hline Variable & Interpersonal network & Interunit network \\
\hline Number of nodes & 196 & 10 \\
Density & 0.010 & 0.322 \\
Average degree & 1.954 & 2.900 \\
Degree standard deviation & 3.201 (in) 3.029 (out) & 1.287 (in) 1.100 (out) \\
Degree skewness & 2.728 (in) 4.985 (out) & 1.290 (in) 0.621 (out) \\
Reciprocity & 0.076 & 0.379 \\
GCC transitive closure & 0.277 & 0.365 \\
GCC cyclic closure & 0.058 & 0.330 \\
\hline
\end{tabular}

meaningful structure was unlikely to emerge, while MERGM analysis of the multilevel network built adopting criteria b. and c. led to similar results. Eventually, we applied criterion c., assuming the existence of an above average number of ties from employees of $h$ to employees of $k$ (with the average computed, for each unit $h$, over the values representing ties to $k$ ) as evidence of the existence of a work-flow tie from unit $h$ to unit $k .{ }^{7}$ For $p$ units:

if $a_{h k} \geq \sum_{k} \frac{a_{h k}}{(p-1)} \quad$ then $a_{h k}=1 \quad$ otherwise $a_{h k}=0$.

We double-checked the structure of network $A$ with alternative sources - i.e., face to face interviews with a sample of employees ${ }^{8}$ and information on the division's activities available from the institutional website. Our network aggregation procedure was consistent with these other sources.

Finally, we used company's archival data on units' composition to reconstruct the affiliation network $X$, sized $(196 \times 10)$. Its generic element $x_{i h}=1$ if individual $i$ is member of unit $h$ and $x_{i h}=0$ otherwise. Table 1 reports the main descriptive statistics for networks $A$ and $B$, like features of the degree distributions and global clustering coefficients - i.e., GCCs (Luce and Perry, 1949).

3.2.2.2. Actor attribute variables. Unit attributes are function and size. Function is used to account for the specialism of each unit's activities and permits verifying the effect of specialism on knowledge transfer. We defined three levels on a categorical scale. The highest level of specialism (six units) corresponds to responsibility on specific activities. The intermediate level (three units) implies responsibility on strategic activities, which typically require a more diversified set of knowledge within similar areas of interest. The lowest level represents coordination of the organization's activities (one unit only). This level requires the capability to understand and integrate the wide range of knowledge that is available in the various units and that the organization exploits to perform its activities. Size was captured as the number of employees affiliated to a unit ( mean $=19.6$; st. dev. $=9.6$; range $=6-33$ ) and is expected to

\footnotetext{
7 We believe that this criterion has the strongest theoretical justification. Dichotomizing ties at the mean value is in line with the definition of interunit ties adopted (i.e., systematic and stable cooperation between groups of people nested in organizational units). It implies that several employees of one unit cooperate with others affiliated to another unit. Also, this criterion accounts for the variability in unit size. Finally, this criterion has the strongest methodological justification: representing a theoretically macro-level variable as the mean value of the measured micro-level variable of which the macro-level variable is a function, is consistent with standard multilevel modeling. Also in this context, it is possible to derive a macro-level variable as a function/aggregation of a micro-level variable, when it makes sense from a theoretically viewpoint. However, we acknowledge that the threshold is somehow arbitrary. For this reason, we performed the robustness checks mentioned in the text using criterion b. and c. In both the cases, we obtained the same results for the configurations linked to the research hypotheses. Also the other effects were very similar. Detailed results on these alternative models are available from the authors.

${ }^{8}$ We showed them a picture of network $A$ and asked to comment on the adequacy of that representation to their perception of the organizational work-flow. As expected, they were able to provide a detailed feedback on the ties involving their unit, but substantially agreed on the overall structure.
} 
Table 2

ERGM effects for interaction within the interpersonal network.

\begin{tabular}{|c|c|c|}
\hline Effect & Configuration & Description \\
\hline Reciprocity & & Tendency to build non-hierarchical relations based on mutual knowledge seeking \\
\hline Popularity spread & & $\begin{array}{l}\text { Tendency for a small number of individuals to be sought by many colleagues as } \\
\text { knowledge sources ('hubs' in the indegree distribution) }\end{array}$ \\
\hline Activity spread & & $\begin{array}{l}\text { Tendency for individuals to seek many colleagues as knowledge sources ('hubs' in } \\
\text { the outdegree distribution) }\end{array}$ \\
\hline 2-Paths & & Tendency for in- and out-degree to be correlated (basic assortativity) \\
\hline Isolates & & Tendency not to be involved in any knowledge-seeking tie \\
\hline Transitive closure & & $\begin{array}{l}\text { Tendency of individual } i \text { who seeks } j \text { indirectly through } h \text { also to directly seek } j \text { for } \\
\text { knowledge (transitivity) }\end{array}$ \\
\hline Cyclic closure & & $\begin{array}{l}\text { Tendency of individual } i \text { who is sought indirectly from } j \text { through } h \text { to directly seek } j \\
\text { for knowledge (generalized exchange) }\end{array}$ \\
\hline Popularity based closure & & $\begin{array}{l}\text { Tendency of individuals who are chosen by the same people as knowledge sources } \\
\text { to form a tie (structural homophily) }\end{array}$ \\
\hline Covariate match & & $\begin{array}{l}\text { Tendency to seek knowledge from colleagues with the same value of a covariate } \\
\text { (homophily) }\end{array}$ \\
\hline
\end{tabular}

Circles represent the individuals and ties represent the seeking new ideas relation. Black denotes the individuals with a specific value of an attribute.

affect interpersonal interaction in two ways. "Large units tend to be more influential than small units and may dominate the knowledge sharing processes in the company. Large units also tend to have more managerial and financial resources to develop new knowledge and may be more attractive to smaller units in search of knowledge" (Tsai, 2002; p. 184). Indeed, larger units are likely to be more involved than others in knowledge transfer, just because they employ more people.

Individual attributes are organizational role and tenure. Role, as proxy of status, captures the attractiveness of people as sources of knowledge (Borgatti and Cross, 2003). We represented role on a categorical scaling with three levels of increasing autonomy and responsibility (Managers 43.9\%; Clerks 30.6\%; Assistants 25.5\%). Organizational tenure captures work experience and is measured as the number of years from when the employee joined the organization ( mean $=7.6$; st. dev. $=9.2$; range $=0.5-15$ ). As the distribution was very skewed, tenure was entered the model with a logarithmic transformation.

\subsection{Model building and effects included}

We start our discussion presenting the ERGM effects used to model the interpersonal network (see Table 2). General theory on knowledge transfer suggests which local configurations are expected to shape the network structure. We fixed network density, to aid model convergence, so we did not need to include an effect for baseline density. We specified the basic tendency toward
Reciprocity. With Popularity and Activity spread we modeled the degree distributions and captured the tendency toward the existence of 'hubs'. ${ }^{9}$ As a control, we added 2-Paths, which tests the correlation between in- and out-degree, suggesting whether the same people are senders and receivers of ties. We included also Isolates to model more accurately the skewness of the degree distributions (Robins et al., 2009).

We captured more complex interdependences with closure mechanisms. In our context, closure is linked to embeddedness and redundancy of information. We included Transitive closure, the most common configuration. Because it frequently does not suffice to explain local closure or can lead to unstable models, we specified also Cyclic closure and Popularity based closure. The former accounts for generalized exchange of knowledge within groups, while the latter models structural homophily and captures the presence of 'hubs' also within groups. Finally, the Covariate match effect accounts for covariate based homophily - i.e., the likelihood that employees select similar others as sources of new ideas. We included this homophily parameter for role and tenure.

Interdependences between the two networks were modeled specifying the cross-level effects (Wang et al., 2013, 2015) (see

\footnotetext{
9 The formula of both Popularity and Activity spread includes a damping paramete $\lambda$, which specifically models the skewness of the degree distribution. $\lambda$ is usually set to 2 , but it is advisable to examine larger values, when the distribution is particularly skewed. $\lambda$ can be increased step by step, until the best fit is obtained (Hunter and Handcock, 2006; Robins and Lusher, 2013).
} 
Table 3

MERGM effects for cross-level interaction between interpersonal and interunit networks.

\begin{tabular}{|c|c|c|}
\hline Effect & Configuration & Description \\
\hline \multicolumn{3}{|l|}{ Cross-level triadic closure } \\
\hline Affiliation based closure arc & & $\begin{array}{l}\text { Tendency to seek knowledge from colleagues who are member in the same unit } \\
\text { (homophily based on common affiliation) }\end{array}$ \\
\hline Affiliation based closure reciprocity & & $\begin{array}{l}\text { Tendency to build mutual ties of seeking knowledge with colleagues who are } \\
\text { member in the same unit }\end{array}$ \\
\hline \multicolumn{3}{|l|}{ Cross-level degree assortativity } \\
\hline In-degree assortativity & & $\begin{array}{l}\text { Tendency of popular individuals in the seeking knowledge network to be affiliated } \\
\text { to popular units in the interunit work-flow network }\end{array}$ \\
\hline Out-degree assortativity & & $\begin{array}{l}\text { Tendency of active individuals in the seeking knowledge network to be affiliated } \\
\text { to active units in the interunit network }\end{array}$ \\
\hline Path assortativity (out/in) & & $\begin{array}{l}\text { Tendency of active individuals in the seeking knowledge network to be affiliated } \\
\text { to popular units in the interunit work-flow network }\end{array}$ \\
\hline Path assortativity (in/out) & & $\begin{array}{l}\text { Tendency of popular individuals in the seeking knowledge network to be affiliated } \\
\text { to active units in the interunit work-flow network }\end{array}$ \\
\hline
\end{tabular}

Cross-level alignment

Alignment entrainment

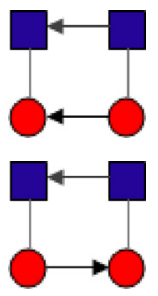

Tendency of individuals to seek knowledge from colleagues affiliated to units which are superordinate in the interunit work-flow network

Alignment exchange

Cross-level alignment covariate match

Alignment entrainment, unit covariate match

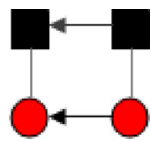

Alignment exchange, unit covariate match

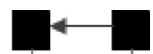

Tendency of individuals to seek knowledge from colleagues affiliated to units which are subordinate in the interunit work-flow network

Tendency of individuals affiliated to units with a given value of a covariate to seek knowledge from colleagues affiliated to units with the same level of the covariate and superordinate in the interunit work-flow network

Tendency of individuals affiliated to units with a given value of a covariate to seek knowledge from colleagues affiliated to units with the same level of the covariate and subordinate in the interunit work-flow network

Tendency of individuals with a given value of a covariate to seek knowledge from colleagues with the same level of the covariate and affiliated to units superordinate in the interunit work-flow network

Alignment exchange, actor covariate match

Tendency of individuals with a given value of a covariate to seek knowledge from colleagues with the same level of the covariate and affiliated to units subordinate in the interunit work-flow network

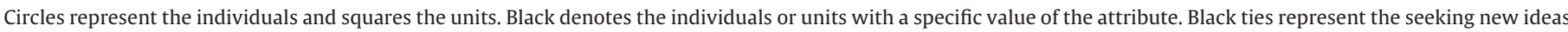
relation among individuals, dark gray ties the workflow relation among units, and light gray ties are affiliation of individuals to a unit. 
Table 3). Because either the affiliations or the organizational structure do not depend on individual or unit choices and are not likely to change, we considered networks $X$ and $A$ as exogenous and kept them fixed during the estimation process. ${ }^{10}$

The first hypothesis is that ties of knowledge transfer are more likely within unit boundaries. We verified it by specifying Affiliation based closure statistics. These configurations capture homophily based on a shared affiliation, a tendency of social relations well documented in the literature (Contractor et al., 2006; Monge and Contractor, 2001). Since we do not know how interaction takes place within unit boundaries, we included two versions of Affiliation based closure statistics. Affiliation based closure arc suggests that interaction is shaped by a local hierarchical ordering, with interpersonal ties in one direction only. Affiliation based closure reciprocity controls for the tendency to build mutual ties, based on a flat hierarchy.

The second hypothesis is that knowledge transfer ties are sustained by interunit work-flow ties. Extant literature points to the dichotomy of tight versus loose coupling between formal and informal relations in organizations (McEvily et al., 2014). Since we have no strong theoretical assumptions on the direction of ties, we included both Cross-level alignment effects. They represent crosslevel mirroring or overlap such that members of connected groups are themselves connected. Alignment entrainment assumes that interunit and interpersonal ties have the same direction. Accordingly, people seek knowledge from colleagues who are members in units on which their own unit depends for work-flow information. This effect points to a hierarchical ordering in interpersonal knowledge transfer due to interunit ties. Alignment exchange assumes that interpersonal and interunit ties have opposite direction. People seek ideas from colleagues who are members in units which depend on their own unit for work-flow information. Hence, this effect assigns an opposite role to units and employees.

The third hypothesis is that connected units with different level of specialism are less likely to sustain interpersonal boundary spanning. We addressed this hypothesis indirectly, specifying Cross-level alignment also as Covariate match for unit level of specialism. Alignment effects test whether members of connected units are more likely to search for new knowledge when the connected units have the same level of specialism. Following the structural part of the model, we included Alignment entraiment and Alignment exchange effects. We expect them both to be positive.

As a control we included the Cross-level assortativity effects. Cross-level in-degree and out-degree assortativity are the MERGM formalization of the structural linked design (Lazega et al., 2008) and represent the tendency for popular/active people to be affiliated to popular/active units. These effects may indicate a 'sidestepped' role of individuals - i.e., centrality of people in the knowledge transfer network is due to the position of their unit in the work-flow network. We controled for the direction of ties including Cross-level path assortativity. This represents the interaction between in-degree of actors at one level and out-degree of actors at the other.

Finally, we accounted for the association between interunit and interpersonal ties due to units and individuals' control covariates. Specifying Alignment entrainment and exchange Covariate match for unit size and people role and tenure, we tested cross-level homophily and verified the impact of exogenous characteristics on the strength of structural multilevel effects.

\footnotetext{
${ }^{10}$ In essence, we are predicting the interpersonal knowledge-seeking network from the rest of the multilevel network (and taking account of the within-network dependences.) As cross-level effects we included statistics for interdependences between interpersonal $(B)$ and affiliation $(X)$ networks and statistics for the association between interpersonal and interunit $(A)$ networks, linked through affiliation.
}

We built the empirical models adopting a forward selection procedure (for a discussion on the various approaches to ERG modeling, see Goodreau, 2007).

We assessed the model goodness of fit using the distribution of networks simulated from the fitted ERGMs and MERGMs (Hunter et al., 2008). We performed the test on the effects included in the model and on a number of other statistics. These include ERGM and MERGM effects not parameterized by the models as well as some crucial network properties. For each network feature we assessed the fit by computing a $t$-ratio, defined as the difference between the value of the statistic in the observed network and the corresponding mean statistic computed over the simulated network sample, divided by the standard error. For a statistic not parameterized in the model a corresponding t-ratio not greater than 2.0 in absolute value is regarded as plausible fit. For an ERGM and MERGM effect in the model, the $t$-ratio must be not greater than 0.1 in absolute value to confirm a converged parameter estimate (Robins and Lusher, 2013). For the network simulations we picked every 10,000 graphs, sampled from $10,000,000$ iteration simulation, after a 100,000 iteration burn-in.

\section{Results}

We specified the effects in an increasing order of complexity (Table 4). Model 1 is the baseline model, Model 2 is the intermediate model, and Model 3 is the multilevel complete model. We comment on the latter, drawing attention to its ability to either improve or simplify the representation of knowledge transfer.

First, we look at the interpersonal network. The positive Reciprocity estimate indicates that knowledge seeking is likely to be a mutual relation, based on knowledge sharing (McFadyen et al., 2009). The positive parameter is also likely to imply a large amount of knowledge transferred and a high level of cooperation and trust (Uzzi and Lancaster, 2003). Conditional on the presence of a tie from $i$ to $j$, and on other effects of the model, the odds of reciprocation are more than sixteen times $(\exp [2.791]=16.297)$ the odds of no reciprocation.

The positive Popularity spread estimate points to a centralization of the in-degree distribution. ${ }^{11}$ Akin to a preferential attachment-type mechanism (Barabási and Albert, 1999), some employees are considered valuable sources of knowledge and are sought by many colleagues. Activity spread, on the other hand, is non-significant indicating little centralization in out-degrees and suggesting that employees are relatively homogeneous in respect to seeking knowledge from others.

The negative 2-Paths estimate indicates that employees who seek ideas from many others are less likely themselves to be sources of ideas. Hence, different individuals are sources and receivers of knowledge.

The parameters for closure effects are all significant and indicate the presence of more complex extra-dyadic network dependences. The positive Transitive closure 'suggests the existence of a cliqueish structure and can be interpreted as the outcome of a path shortening process, whereby connectivity in the form of multiple two-paths leads to a direct tie' (Robins et al., 2009, p. 106). The combination between positive Transitive closure and negative Cyclic closure offers insights on how triangles are formed. Knowledge search-transfer is shaped by a propensity toward clustering in local hierarchical subgroups and against generalized exchange (Bearman, 1997). The positive Popularity based closure suggests that popular sources of ideas themselves seek knowledge from each other. Together, these parameters indicate that knowledge

\footnotetext{
11 As demonstrated by the high value of the parameter $\lambda$, the distribution is also very skewed.
} 
Table 4

ERGM and MERGM estimates.

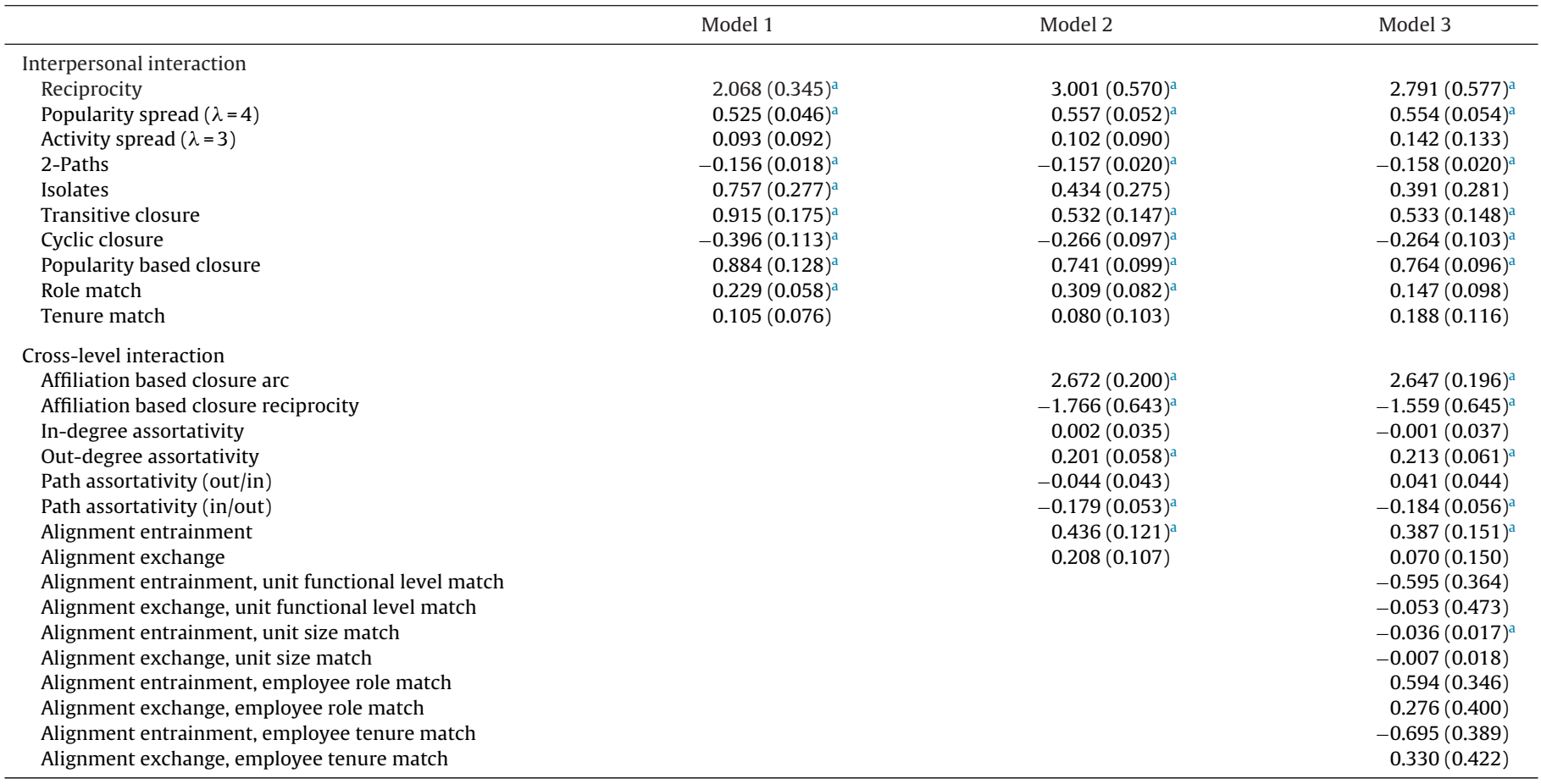

${ }^{\text {a }}$ Indicates that the ratio of statistic to standard error is greater than 2 (standard errors in parentheses).

transfer takes place mainly within hierarchical sub-groups. Triangles tend to close around knowledgeable employees, who are popular sources of new knowledge.

The non-significant Tenure match underlines that similarity in organizational seniority does not affect individual tendency toward knowledge searching. Broadly, all these effects are preserved in the three models with a couple of exceptions. The Isolates parameter affects positively the knowledge seeking in Model 1, indicating that there are more isolated employees than would be expected from the other effects in the model. However, this effect ceases to be significant in Models 2 and 3. Also Role match - the propensity toward seeking colleagues in the same role - is positively significant in Model 1 and 2, but disappears in Model 3, once we control for a cross-level influence of the same effect. This result suggests that heterogeneity among individuals in their tendency to interact is due to self-organizing mechanisms of tie formation, not to individual characteristics.

MERGM effects specified in Models 2 and 3 examine the influence of the formal organizational structure of work-flow ties on interpersonal knowledge search-transfer.

In respect to the first hypothesis, the positive estimate of the Affiliation based closure arc indicates that employees tend to go for knowledge to colleagues affiliated to the same unit, and are unlikely to cross-cut unit boundaries. In line with expectations, units are likely to retain interpersonal ties within their boundaries. The significantly negative Affiliation based closure reciprocity suggests that knowledge search ties do not tend to be reciprocated within unit boundaries. Hence, search-transfer preserves a sort of local hierarchical ordering. Considered together with the general tendency toward reciprocity, the negative propensity toward within unit reciprocity implies that knowledge searchtransfer is based on weak ties among individuals within units, and more on mutual or strong ties between individuals from different units.

In respect to the second hypothesis, the significantly positive Alignment entrainment effect indicates that people tend to seek knowledge from colleagues affiliated to units connected to their own by work-flow ties. In line with expectations, knowledge seeking ties are likely to cross-cut unit boundaries when sustained by interunit work-flow ties. The combination between the significantly positive Alignment entrainment and the non-significant exchange parameter suggests that interpersonal and interunit ties have the same direction. Hence, knowledge seeking is likely to be initiated by people affiliated to superordinate units in day to day activities and aligns to the hierarchical ordering established between units.

In respect to the third hypothesis, the non-significant Alignment entrainment and exchange parameters for functional level of specialism match indicate that the propensity for members in connected units to be themselves connected is not affected by the level of specialism of the units. Apparently, knowledge transfer ties between people affiliated to different units are not less likely when the units linked by work-flow ties have a different level of specialism.

The control effects add some insights on the influence of the organizational structure on interpersonal knowledge searchtransfer. The significantly positive Out-degree assortativity points to the association between out-degree centrality at the two levels. Individuals more active in seeking ideas are affiliated to units more reliant on others in day to day cooperation. Individual propensity toward sampling the ideas of their colleagues, then, may be due, at least partly, to the fact that the individuals concerned may be used to relying on others in day to day activities. The impact of unit centrality is strengthened by the significantly negative Path assortativity (in/out) effect, indicating that association between people popularity and unit activity is unlikely.

Finally, the negative Alignment entrainment unit size match effect shows that people are less likely to search for new knowledge from members of connected units when the units have a similar number of employees. In other words, the tightness of the aligned knowledge flows is particularly so when a smaller unit seeks knowledge from a larger unit or vice versa. None of the other covariates is statistically significant. 
Table 5

Goodness of fit of ERGM and MERGM estimates.

\begin{tabular}{|c|c|c|c|c|c|c|c|}
\hline \multirow[t]{2}{*}{ Statistics } & \multirow[t]{2}{*}{ Observed } & \multicolumn{2}{|l|}{ Model 1} & \multicolumn{2}{|l|}{ Model 2} & \multicolumn{2}{|l|}{ Model 3} \\
\hline & & Simulated & $t$-ratio & Simulated & $t$-ratio & Simulated & $t$-ratio \\
\hline St. dev. in-degree distrib. & 3.201 & 3.140 & 0.337 & 3.040 & 1.017 & 3.096 & 0.461 \\
\hline Skewness in-degree distrib. & 2.728 & 2.305 & 1.409 & 2.199 & 1.935 & 2.480 & 1.340 \\
\hline St. dev. out-degree distrib. & 3.029 & 3.038 & -0.020 & 2.608 & 1.667 & 2.830 & 1.194 \\
\hline Skewness out-degree distrib. & 4.985 & 3.601 & 1.685 & 2.350 & 5.165 & 3.418 & 1.790 \\
\hline GCC transitive closure & 0.277 & 0.329 & -1.128 & 0.311 & -0.863 & 0.341 & -1.278 \\
\hline GCC cyclic closure & 0.058 & 0.070 & -0.590 & 0.066 & -0.340 & 0.060 & -0.124 \\
\hline
\end{tabular}

We concluded our analysis with the goodness of fit check. ${ }^{12}$ Table 5 summarizes the goodness-of-fit diagnostics of the overall network properties, showing that the three models are capable of reproducing most of them. In Model 3, in particular, the t-ratios for standard deviation and skewness of the degree distributions, as well as for the global clustering coefficients (GCCs), are all well below the threshold, i.e., 2.0 in absolute value.

Also the t-ratios of the statistics parameterized by the models are close to 0.1 in absolute value. Overall, the number of statistics well fitted is 38 out of the 73 that can be specified for the complete MERGMs with attribute effects in Model 1, 51 in Model 2 and 71 in Model 3. What Model 1 obviously does not do well is fit the cross-level effects at all well. Only parameterizing cross-level effects allows capturing interdependences across levels.

\section{Discussion and conclusions}

Studies on organizational learning have long emphasized the role of interpersonal ties spanning unit boundaries as the main conduit through which knowledge flows within the organization. Although recognizing the hierarchical nature of organizations, these studies have treated organizational units as independent, and investigated relational and individual characteristics that allow organizational members to cross-cut boundaries. In this paper we have taken a different perspective, focusing on organizational characteristics. We have claimed that the macro-level structure of interunit formal ties can affect interpersonal knowledge transfer in more complex ways than studies on boundary spanning have assumed. Hierarchical formal relations of cooperation between units - as mapped by the work-flow - and the level of specialism of the connected units can sustain boundary-spanning interaction between some parts of the organization and hinder it between some others.

Modeling knowledge flow between organizational members, we have provided evidence of the local mechanisms that shape interpersonal interaction across levels of analysis.

We have verified that - in line with previous findings - knowledge search-transfer is generally more likely to occur within the same unit. Interesting enough, however, organizational members tend to span unit boundaries, seeking knowledge from colleagues affiliated to a different unit, if the two units are already connected by formal work-flow ties. Systematic interaction in day to day activities, then, helps people develop familiarity, awareness and better understanding of the knowledge available in connected units and reduces people's reluctance toward building cross-cutting ties. The alignment between interpersonal and interunit ties suggests, moreover, that knowledge search-transfer is based on a division of roles between people searching and others providing knowledge. This division reflects the hierarchical ordering imposed by interunit formal relations and suggests a subordination of knowledge transfer

\footnotetext{
12 Since the affiliation and the higher-level networks were kept fixed, we could examine the structural features of the interpersonal network only.
}

to formal organizational processes of interunit cooperation. Finally, the different level of specialism of connected units does not affect people's propensity toward searching-transferring knowledge. Once interunit ties induce familiarity and understanding between people that are members in different units, the dissimilarity between the specific functional level of the units - in terms of specialism - does not prevent people from searching-transferring knowledge.

In addition, we have found that people more active in seeking knowledge from colleagues are affiliated to units that are more involved in day to day cooperation. Besides individual propensity toward building ties, membership to a central unit in the workflow network seems to explain people's centrality in the knowledge search-transfer network.

In highlighting these results, our study makes an original contribution to the literature on organizational learning. Understanding how informal interpersonal interaction is sustained by the formal organizational structure helps organizations that want to foster organizational learning to develop a fit between formal and informal structures (Krackhardt and Hanson, 1993), and support interaction across boundaries by means of job rotation, compensation, promotions and performance evaluations (Cross et al., 2001).

This paper also contributes to the broad literature on social networks in organizational settings. Our results suggest that crucial properties of social networks that have been frequently used to explain interpersonal interaction weaken, once the formal organizational structure of interunit ties is accounted for, or are mediated by it. This consideration holds for centrality, as illustrated above, and for homophily. The propensity of people to seek knowledge from colleagues with similar tenure and role values - the workrelated attributes included in our empirical models - disappears in the multilevel model. Results have to be interpreted cautiously, because various significant variables have not been tested (i.e., gender, educational level, etc.), but could indicate that participation and role of people in interpersonal networks are tightly linked to the formal organizational structure of interunit ties in which relations take place. Accounting for the formal structure in studying interpersonal networks would allow better detecting at which organizational level (i.e., micro versus macro level) a phenomenon occurs and assessing the real contribution of informal networks. For example, this point would be crucial in innovation studies, which emphasize the importance of understanding whether exploration and recombination of new ideas is initiated by the organization as a whole or by individuals within the organization (Phelps et al., 2012).

In this respect, we contribute to the increasing body of literature on organizations as multilevel network systems, proposing Multilevel Exponential Random Graph Models as a suitable method for addressing the effects of interunit formal ties on interpersonal informal ties. We have shown that MERGMs allow assessing these effects directly, specifying them as various mechanisms of crosslevel dependence. Although MERGMs are cross-sectional models for network ties, and do not permit any causal claims on individual strategies of partner selection, MERGM mechanisms offer 
interesting insights on how people adapt and react to an exogenous organizational structure. This aspect, as well as the others mentioned above, deserves further examination in future research.

The call for more research on the topic stems also from the main limitations of this study. It is useful to reflect on them to reduce the risk of over-interpreting the results. A first limitation is that we have used interunit ties of information flow to capture formal cooperation in day to day activities between units. Although we think that our approach is consistent with the most common definition of cooperation between units (Hansen, 1999), it is also the case that it is frequently represented by organizational 'written instructions or protocols' on how activities have to be performed and cooperation has to be organized. We have also selected for analysis one specific relation, observed at interpersonal level, to infer the existence of interunit ties. We have justified our choice, and have illustrated the theoretical and statistical concerns that make reasonable the representation of formal cooperation as a relation among units. Also, we have attempted to ensure a more objective representation of interunit ties by double-checking the resulting network structure with interviews and secondary data on cooperation among units. However, in future work, it would be good for researchers to reflect on how best to measure interunit work-flow ties.

Another limitation stems from the available data. We have included a number of covariates that can explain the individual propensity toward boundary spanning as well as the selection of a given unit as target of boundary spanning ties. Other covariates, however, could not enter our model or had to be specified in a simple way. For example, besides the units' level of specialism, it could have been interesting to account for their formal goals or knowledge set. This would have allowed assessing the extent of similarity versus complementarity between the knowledge exploited in connected units, and better explain the presence or lack of interpersonal ties. Similarly, it could have been useful to include other people attributes, like the job task or the educational level. Third, and in conclusion, we have conducted our study on a single organization. The consistency of results on the interpersonal knowledge search-transfer network with findings of prior studies seems to show that the dynamics shaping our empirical setting do not differ from those widely outlined in extant literature on organizational learning and boundary spanning. This consideration, then, could be cautiously extended to our original results on cross-level dependences. However, our case study cannot be seen as representative of all organizations. In this regard, we concede that public administration is usually characterized by a moderate interest in learning processes. This moderate interest is likely to be fairly common to most non-innovation oriented companies. Nevertheless, it would be interesting to verify whether and how our findings generalize to other types of organizations. In spite of these limitations, we think that the conclusions we have reached may guide researchers in hypothesizing effects in further work in this area. The novelty of the multilevel network approach to organizations and of the MERGM framework makes our study an interesting starting point to examining organizational behavior through a multilevel network lens.

\section{References}

Argote, L., Epple, D., 1990. Learning curves in manufacturing. Science 247 (4945), 920-924.

Argote, L., Ingram, P., 2000. Knowledge transfer: a basis for competitive advantage in firms. Organ. Behav. Hum. Decis. Process. 82 (1), 150-169.

Argote, L., McEvily, B., Reagans, R., 2003. Managing knowledge in organizations: an integrative framework and review of emerging themes. Manage. Sci. 49 (4), 571-582.

Barabási, A.L., Albert, R., 1999. Emergence of scaling in random networks. Science 286 (5439), 509-512.

Barnett, W.P., Greve, H.R., Park, D.Y., 1994. An evolutionary model of organizational performance. Strateg. Manage. J. 15 (S1), 11-28.
Baum, J., Ingram, P., 2002. Interorganizational learning and network organization: toward a behavioral theory of the interfirm. The economics of choice, change, and organization: essays in memory of Richard M. Cyert, 191-218.

Bearman, P. 1997. Generalized exchange 1. Am. J. Sociol. 102 (5), 1383-1415.

Beckman, C.M., Haunschild, P.R., 2002. Network learning: the effects of partners' heterogeneity of experience on corporate acquisitions. Adm. Sci. Q. 47 (1), 92-124.

Beckman, C.M., Haunschild, P.R., Phillips, D.J., 2004. Friends or strangers? Firmspecific uncertainty, market uncertainty, and network partner selection. Organ. Sci. 15 (3), 259-275

Borgatti, S.P., Cross, R., 2003. A relational view of information seeking and learning in social networks. Manage. Sci. 49 (4), 432-445.

Borgatti, S.P., Foster, P.C., 2003. The network paradigm in organizational research: a review and typology. J. Manage. 29 (6), 991-1013.

Brass, D.J., Galaskiewicz, J., Greve, H.R., Tsai, W., 2004. Taking stock of networks and organizations: a multilevel perspective. Acad. Manage. J. 47 (6), 795-817.

Burt, R.S., 1992. The social structure of competition. In: Nohria, N., Eccles, R. (Eds.), Networks and organizations: Structure, Form, and Action. Harvard Business School Press, Boston, pp. 57-91

Burt, R.S., 2004. Structural holes and good ideas. Am. J. Sociol. 110 (2), 349-399.

Carroll, G.R., 1985. Concentration and specialization: dynamics of niche width in populations of organizations. Am. J. Sociol. 90 (6), 1262-1283.

Cohen, W., Levinthal, D., 1990. Absorptive capacity: a new perspective on learning and innovation. Adm. Sci. Q. 35 (1), 128-152.

Contractor, N.S., Wasserman, S., Faust, K., 2006. Testing multitheoretical, multilevel hypotheses about organizational networks: an analytic framework and empirical example. Acad. Manage. Rev. 31 (3), 681-703.

Cross, R., Parker, A., Prusak, L., Borgatti, S., 2001. Knowing what we know: supporting knowledge creation and sharing in social networks. Organ. Dyn. 30 (2), 100-120.

Cyert, R., March, J., 1963. A Behavioral Theory of the Firm, vol. 2. Cambridge, MA, Englewood Cliffs.

Damanpour, F., 1991. Organizational innovation: a meta-analysis of effects of determinants and moderators. Acad. Manage. J. 34 (3), 555-590.

Dokko, G., Kane, A.A., Tortoriello, M., 2014. One of us or one of my friends: how social identity and tie strength shape the creative generativity of boundary-spanning ties. Organ. Stud. 35 (5), 703-726.

Epple, D., Argote, L., Devadas, R., 1991. Organizational learning curves: a method for investigating intra-plant transfer of knowledge acquired through learning by doing. Organ. Sci. 2 (1), 58-70.

Feld, S.L., 1981. The focused organization of social ties. Am. J. Sociol. 86 (5), 1015-1035.

Fiske, S.T., Taylor, S.E., 1984. Social Cognition. Random House, New York.

Goodreau, S., 2007. Advances in exponential random graph ( $\left.\mathrm{p}^{*}\right)$ models applied to a large social network. Soc. Netw. 29 (2), 231-248.

Granovetter, M., 2005. The impact of social structure on economic outcomes. J. Econ Perspect. 19 (1), 33-50.

Granovetter, M.S., 1973. The strength of weak ties. Am. J. Sociol. 1 (1), 1360-1380

Handcock, M., Gile, K., 2010. Modeling social networks from sampled data. Ann. Appl. Stat. 4 (1), 5-25.

Hansen, M., 1999. The search-transfer problem: the role of weak ties in sharing knowledge across organization subunits. Adm. Sci. Q. 44 (1), 82-111.

Hitt, M.A., Texas, A., Jackson, S.E., Zurich, G., 2007. Building theoretical and empirica bridges across levels: multilevel research in management. Acad. Manage. 50 (6), 1385-1399.

Hunter, D.R., Handcock, M.S., 2006. Inference in curved exponential family models for networks. J. Comput. Graph. Stat. 15 (3), 565-583.

Hunter, D., Goodreau, S., Handcock, M., 2008. Goodness of fit of social network models. J. Am. Stat. Assoc. 103 (481), 248-258.

Ingram, P., Baum, J.A., 1997. Opportunity and constraint: organizations' learning from the operating and competitive experience of industries. Strateg. Manage. J. 18 (s 1), 75L 98

Kleinbaum, A.M., Stuart, T.E., Tushman, M.L., 2013. Discretion within constraint: homophily and structure in a formal organization. Organ. Sci. 24 (5), 1316-1336.

Kogut, B., Zander, U., 1996. What firms do? Coordination, identity, and learning. Organ. Sci. 7 (5), 502-518.

Kossinets, G., 2006. Effects of missing data in social networks. Soc. Netw. 28 (3) $247-268$.

Kozlowski, S.W., Klein, K.J., 2000. A multilevel approach to theory and research in organizations: contextual, temporal, and emergent processes. In: Kozlowski S.W., Klein, K.J. (Eds.), Multilevel Theory, Research, and Methods in Organizations: Foundations, Extensions, and New Directions. Jossey-Bass, San Francisco, pp. 3-90.

Krackhardt, D., Hanson, J., 1993. Informal networks: the company behind the chart Harv. Bus. Rev. 71 (4), 104-111.

Lazega, E., Jourda, M.T., Mounier, L., Stofer, R., 2008. Catching up with big fish in the big pond? Multi-level network analysis through linked design. Soc. Netw. 30 (2), 159-176.

Lomi, A., Lusher, D., Pattison, P.E., Robins, G., 2014. The focused organization of advice relations: a study in boundary crossing. Organ. Sci. 25 (2), 438-457.

Luce, R.D., Perry, A.D., 1949. A method of matrix analysis of group structure. Psychometrika 14 (1), 95-116.

March, J.G., 1996. Continuity and change in theories of organizational action. Adm. Sci. Q. 41 (2), 278-287.

March, J.G., 1991. Exploration and exploitation in organizational learning. Organ. Sci. 2 (1), 71-87.

March, J.G., Simon, H.A., 1958. Organizations. Wiley, Oxford. 
McEvily, B., Soda, G., Tortoriello, M., 2014. More formally: rediscovering the missing link between formal organization and informal social structure. Acad. Manage. Ann. 8 (1), 299-345.

McFadyen, M., Semadeni, M., Cannella, A., 2009. Value of strong ties to disconnected others: examining knowledge creation in biomedicine. Organ. Sci. 20 (3), 552-564.

McGrath, J., Argote, L., 2001. Group processes in organizational contexts. In: Hogg M.A., Tindale, R.S. (Eds.), Blackwell Handbook of Social Psychology: Group Processes. Blackwell, Oxford, pp. 603-627.

Mintzberg, H., 1979. The Structuring of Organizations. Prentice Hall, Englewood Cliffs, NJ.

Moliterno, T.P., Mahony, D.M., 2011. Network theory of organization: a multilevel approach. J. Manage. 37 (2), 443-467.

Monge, P., Contractor, N., 2001. Emergence of communication networks. In: Jablin, F.M., Putnam, L.L. (Eds.), The New Handbook of Organizational Communication: Advances in Theory, Research, and Methods. Sage, Thousand Oaks, CA, pp. 440-502.

Nonaka, I., 1994. A dynamic theory of organizational knowledge creation. Organ. Sci. 5 (1), 14-37.

Oh, H., Labianca, G., Chung, M.H., 2006. A multilevel model of group social capital. Acad. Manage. Rev. 31 (3), 569-582.

Phelps, C., Heidl, R., Wadhwa, A., 2012. Knowledge, networks, and knowledge networks: a review and research agenda. J. Manage. 38 (4), $1115-1166$

Polanyi, M., 1966. The Tacit Dimension. Anchor Day Books, New York.

Rank, O.N., Robins, G.L., Pattison, P.E., 2010. Structural logic of intraorganizational networks. Organ. Sci. 21 (3), 745-764.

Reagans, R., McEvily, B., 2003. Network structure and knowledge transfer: the effects of cohesion and range. Adm. Sci. Q. 48 (2), 240-267.

Reagans, R., Zuckerman, E.W., 2001. Networks, diversity, and productivity: the social capital of corporate R\&D teams. Organ. Sci. 12 (4), 502-517.

Ren, Y., Argote, L., 2011. Transactive memory systems 1985-2010: an integrative framework of key dimensions, antecedents, and consequences. Acad. Manage. Ann. 5 (1), 189-229.

Robins, G., Lusher, D., 2013. Illustrations: simulation, estimation and goodness of fit. In: Lusher, D., Koskinen, J., Robins, G. (Eds.), Exponential Random Graph Models for Social Networks: Theory, Methods and Applications. Cambridge University Press, Cambridge, pp. 167-186.
Robins, G., Pattison, P., Kalish, Y., Lusher, D., 2007. An introduction to exponential random graph (p*) models for social networks. Soc. Netw. 29 (2), 173-191.

Robins, G., Pattison, P., Wang, P., 2009. Closure, connectivity and degree distributions: exponential random graph $\left(\mathrm{p}^{*}\right)$ models for directed social networks. Soc. Netw. 31 (2), 105-117.

Rousseau, D.M., 1985. Issues of level in organizational research: multi-level and cross-level perspectives. Res. Organ. Behav. 7 (1), 1-37.

Snijders, T., 2002. Markov chain Monte Carlo estimation of exponential random graph models. J. Soc. Struct. 3 (2), 1-40.

Snijders, T., Pattison, P., Robins, G., Handcock, M., 2006. New specifications for exponential random graph models. Sociol. Methodol. 36 (1), 99-153.

Soda, G., Zaheer, A., 2012. A network perspective on organizational architecture performance effects of the interplay of formal and informal organization. Strateg. Manage. J. 33 (6), 751-771.

Tortoriello, M., Krackhardt, D., 2010. Activating cross-boundary knowledge: the role of Simmelian ties in the generation of innovations. Acad. Manage. J. 53 (1), $167-181$.

Tortoriello, M., Reagans, R., McEvily, B., 2012. Bridging the knowledge gap: the influence of strong ties, network cohesion and network range on the transfer of knowledge between organizational units. Organ. Sci. 23 (4), 1024-1039.

Tsai, W., 2002. Social structure of competition within a multiunit organization: coordination, competition, and intraorganizational knowledge sharing. Organ. Sci. 13 (2), 179-190.

Tushman, M., 1977. Special boundary roles in the innovation process. Adm. Sci. Q. 22 (4), 587-605.

Uzzi, B., Lancaster, R., 2003. Relational embeddedness and learning: the case of bank loan managers and their clients. Manage. Sci. 49 (4), 383-399.

Wang, P., Robins, G., Pattison, P., Lazega, E., 2013. Exponential random graph models for multilevel networks. Soc. Netw. 35 (1), 96-115.

Wang, P., Robins, G., Pattison, P., Lazega, E., Jourda, M.T., 2015. Social selection models for multilevel networks. Soc. Netw. http://dx.doi.org/10.1016/j.socnet.2014.12. 003

Williams, K.Y., O'Reilly, C.A., 1998. Demography and diversity in organizations: a review of 40 years of research. Res. Organ. Behav. 20, 77-140.

Zaheer, A., McEvily, B., 1999. Bridging ties: a source of firm heterogeneity in competitive capabilities. Strateg. Manage. J. 20 (12), 1133-1156.

Zander, U., Kogut, B., 1995. Knowledge and the speed of the transfer and imitation of organizational capabilities: an empirical test. Organ. Sci. 6 (1), 76-92. 